\title{
Significance of Hydro-geological and Hydro-chemical Analysis in the Evaluation of Coastal Groundwater Resources in Eastern India
}

\author{
Dr. Amartya Kumar Bhattacharya, Dr. Sudip Basack, Prabir Maity \\ Professor, Department of Applied Mechanics, Bengal Engineering and Science University, Shibpur Howrah- \\ 711103, West Bengal, INDIA. \\ Associate Professor, Department of Applied Mechanics, Bengal Engineering and Science University, Shibpur \\ Howrah - 711103, West Bengal, INDIA. \\ Research Scholar, Department of Applied Mechanics, Bengal Engineering and Science University, Shibpur \\ Howrah - 711103, West Bengal, INDIA.
}

\begin{abstract}
The work described in this paper is aimed towards conducting a thorough and in-depth field based study on the groundwater development and water quality variation in the district of Purba Medinipur, West Bengal, India. 20 nos. locations were selected along the coastal belt of the study area to investigate the groundwater quality. Based on the field test results,contour line were plotted for Chloride concentration. The 3Dimensional views of piezometric surface pre monsoon [ 2006 ], pre-monsoon and post-monsoon average piezometric surfaces [2004] had also been developed. The subsurface characterization and the groundwater quality analysis were thereafter utilized to obtain the probable path of saline water ingress into the aquifers of the study area. Owing to heterogeneity of the aquifer in the selected locations, the spatial irregularity in salinity was observed to be significant. The present study was carried out to understand the quality of ground water and delineate the subsurface formations in an area of Purba Midnapur district. The physico chemical studies involve $\mathrm{pH}$ value, hydraulic conductivity, total hardness, anions $(\mathrm{HCO}, \mathrm{Cl}, \mathrm{CO})$ and $\mathrm{Fe}$.
\end{abstract}

\section{INTRODUCTION}

The country of India has a significantly long coastal belt of $5700 \mathrm{~km}$. The east coat, also named specifically as 'Coromandel' coast, is extended from the state of West Bengal to Kanyakumari, Tamil Nadu. The west coast on the other hand, which is named as 'Konkan' coast, is stretched from Kanyakumari to the state of Gujrat. A brief study on the degree and extent of saline water intrusion in this coastal India has been carried out by Bhattacharya and Basack (2005). It has been observed that the intrusion in the east coast is severe in comparison to the west coast except the state of Gujrat and a limited portion of the state of Maharashtra. All parts of the east coast of India do not have the same susceptibility to saline water intrusion. The east cost of India has a number of deltaic regions. For examples are the Ganga delta, the Mahanadi delta, the Godavari delta, the Krishna delta and the Cauvery delta. In all of these deltas, there is significant recharge in to the aquifer from the upstream, this counteracts to some extent saline water intrusion. There are also places on the east coast of India like Vishakhapattanam where the Eastern Ghats (which is a range of hills running parallel to the coastline) touches the sea. Here saline water intrusion is of no importance. Saline water intrusion is of great importance in locations having diverse characteristics, viz., the Purba Midnapur District of West Bengal which lies on the western fringe of the Ganga delta; the Sundarban area of West Bengal which incised by several tidal channels allowing seawater to proceed deep inland; and Chennai, which is a metropolitan city, located on the seacoast. Each of these sites has its own unique scenario in terms of population, land use, flora and fauna, water consumption pattern, etc. and therefore, each of these merits a separate study. To begin with, the district of Purba Midnapur of West Bengal lying on the western fringe of the Ganga delta is studied in details.

\section{OVERVIEW OF AVAILABLE LITERATURE}

In the Review of Literature the main sources explored were the journals, conferences proceedings and other study materials. The review has been carried out on a global basis with due emphasis given to Indian publications. The relevant contributions have been summarised under the following broad categories, identified as: theoretical contributions, laboratory-based experimental works and field-based studies. The most important contributions by various researchers relevant to the above-mentioned categories are briefly discussed in the following sections. 


\section{THEORETICAL CONTRIBUTIONS}

Li and Yeh (1968) provided a theoretical study on the dispersion at the interface of miscible liquids flow through a porous media. The dispersion at the interface could be described by Fick's law with a velocity dependent coefficient. Firstly, to reveal the effects of gravity and difference in density and viscosity for the flow in the zone of dispersion, a simple two dimensional steady state flow of two liquid in the horizontal direction was studied. It was assumed that in many cases, one of the fluids remains at rest over the other. These are shown in Fig. 1. The author concluded that the zone of dispersion was wider when one of the liquid is at rest.
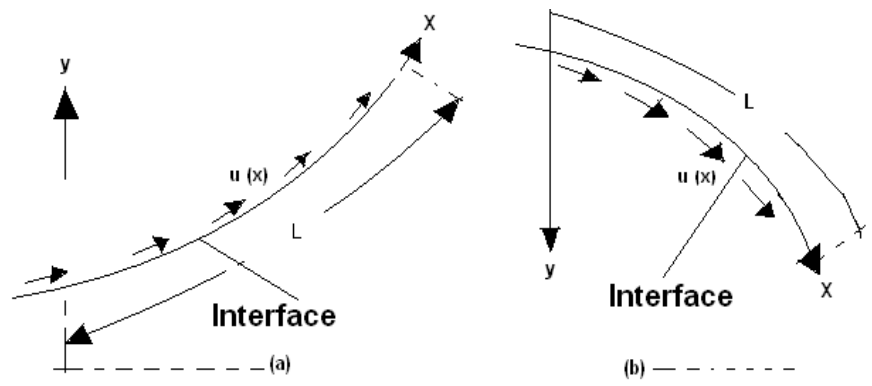

Fig. 1 : Phenomenon of miscible liquid flow through porous medium in case of :

(a) flow over a heavier liquid at rest, (b) flow under a lighter liquid at rest (after Li \& Yeh,1968 ).

Xue et al. (1995) proposed a finite element method to analyse the three dimensional miscible transport model for sea water intrusion in a phreatic aquifer with a transition zone. This model considers many important factors such as: the effect of variable density of fluid flow, precipitation in filtration, phreatic surface fluctuation on the process of sea water intrusion, existence of great discharge pumping wells, etc. Appropriate equations were employed to describe the sea water intrusion in transition zone for the flow of variable density fluid (mixture of fresh water and sea water) and also the transport of dissolved salt. The model was validated with the actual regional data of the study area (China) with reasonable good agreement.

Andrade et al. (1999) investigated the origin of the deviations from the classical Darcy law by numerical simulation of the Navier-Strock equations in two-dimensional disordered porous media. They applied the Forchheimer equation as a phenomenological model to correlate the variations of the friction factor for different porosities and flow conditions. At sufficiently high Reynolds numbers when the inertia becomes relevant, a transition from linear to non-linear behaviour was observed. They found that such transition could be understood and statistically characterized in terms of the special distribution of kinetic energy in the system.

Rudraiah (2001) carried out a theoretical analysis for non-linear flow of stratified fluid through porous media. Solution was obtained for the fluid in motion owing both the constant density gradient as well as piecewise density gradient. The uniform density gradient was found to initiate a purely horizontal motion satisfying the non-linear Forchheimer equation. The author also observed that the vertical density gradient varies continuously in the space time frame, with the horizontal density gradient remaining unchanged. In the case of a piecewise constant density gradient, a stream function formulation was used and the solution were obtained using time-series analysis.

Mahesha (2009) developed a conceptual model for safe withdrawal of fresh water from coastal aquifers. A Galerkin finite-element model was applied considering a sharp interface. Analysis was done introducing a semi pervious sub surface barrier to control the possible advancement of the interface due to withdrawal of fresh water (Fig.2). Using numerical model, the author studied the patterns of the steady state interface profiles, the cone of depression, the upconing and the interface advancement (Fig 3).

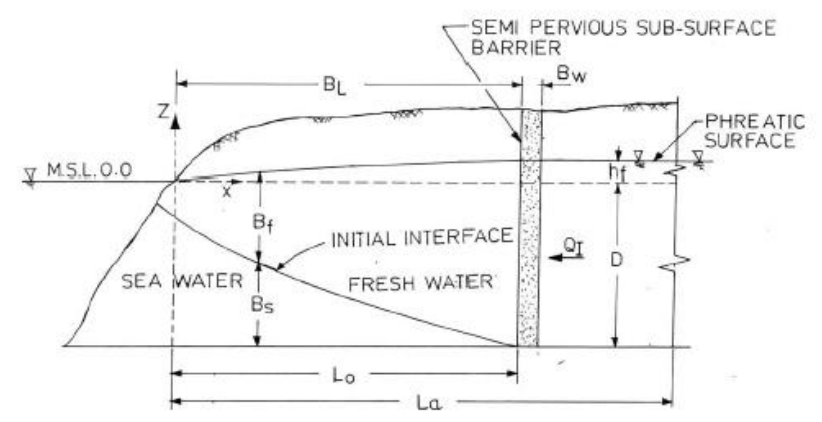

Fig. 2 : The problem definition of Mahesha, 2009. 


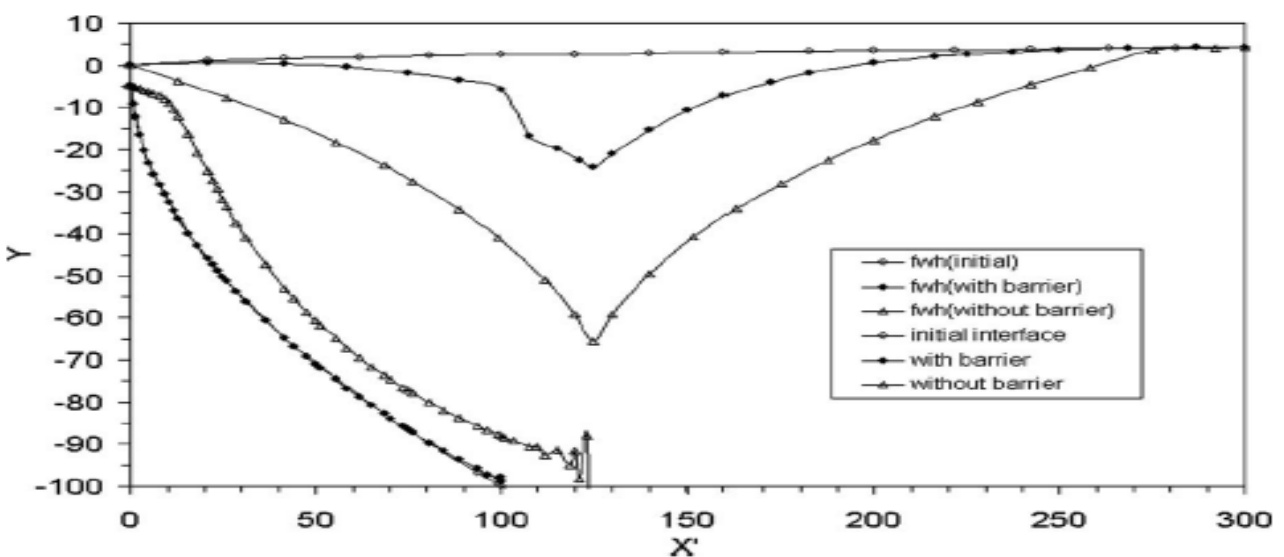

Fig. 3 : Numerical result for : (a) upconing, (b) interface advancement ( after Mahesha, 2009). Laboratory Based Experimental Works

Fand et al. (1987) conducted an experimental investigation for the resistance to the flow of fluids through simple and complex porous media whose matrices were composed of randomly packed spheres. In this context, the terms 'Simple' and 'complex' were referred to porous matrices having the same different sphere diameters respectively. The objective of this study was to obtain useful correlations to relate the pressure gradient the velocity of fluids through porous media. The test section was a stainless steel water tunnel through which the water was either pumped or gravity-fed with a calibrated orifice oblate to measure the flow rate ( Fig. 4). An electrically heated section and a water cooled concentric tube heat exchanger were incorporated for temperature control. The pressure drop across the test section was measured a differential pressure cell for low pressure differences and by means of a series of manometers for higher pressure differences. Darcy flow occurred for simple media for Reynolds number less than 2.3, and the Kozeny-Carman constant equal to 5.34 and the Forchheimer flow occured for Reynolds number between 5 and 80, and Eargun constants between 182 and 5. For complex media, on the other hand, theDarcy flow occured for Reynolds number not exceeding 2.3 and the Kozeny-Carman constant equal to 5.3 and Forchheimer flow occurred for Reynolds number between 5 and 80 and the Eargun constants are 182 and 1.92.

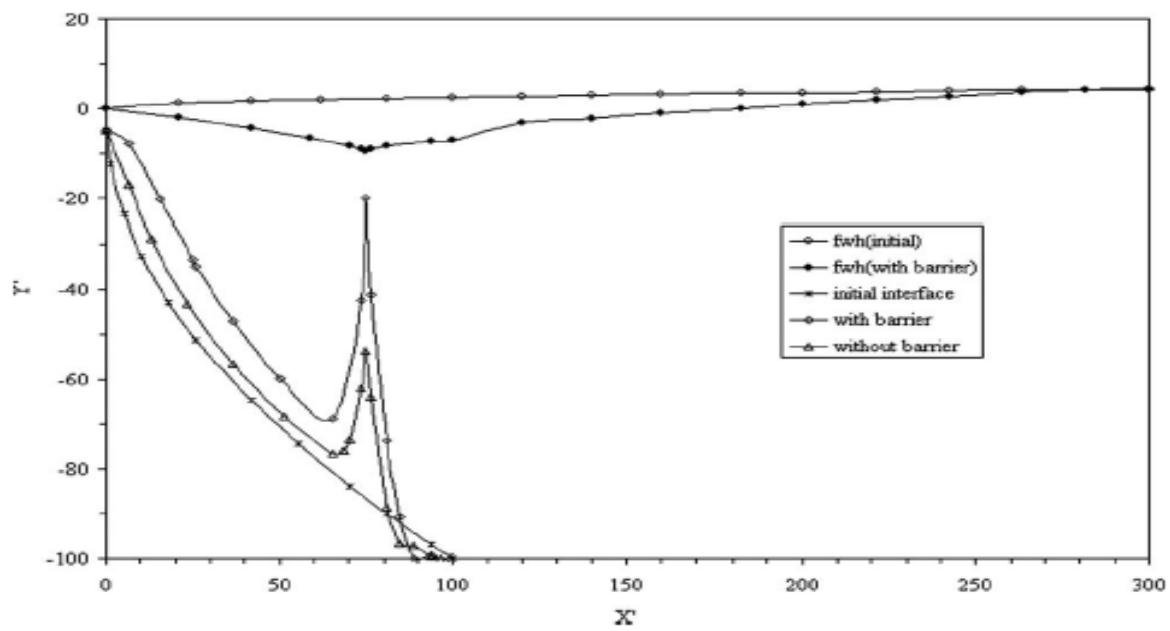

Fig. 4 : Test section of water tunnel, after Fand et al. (1987).

Kececioglu and Jiang (1994) conducted an experimental investigation for flow through porous media of packed spheres saturated with water. The objective of this study was to provide experimental evidence for determining the demarcation criteria for flow through a bed of randomly packed spherical beads. The test set up consisted of a Plexiglas cylindrical tube filled with uniformly sized glass beads (Fig. 5). Water was either pumped or gravity fed via a loop instrumented with flow meters. The pressure differences were measured by either pressure transducer or manometers. As observed Darcy's law has a very limited applicability for Reynolds number less than 0.12 ( Pre-Darcy flow). Also, Forchheimer flow was valid for a Reynolds number less than 2.3. The results also suggested that the pressure drop in Forchheimer equation could be modelled by an approximately non-dimensionalized Ergun's equation. 


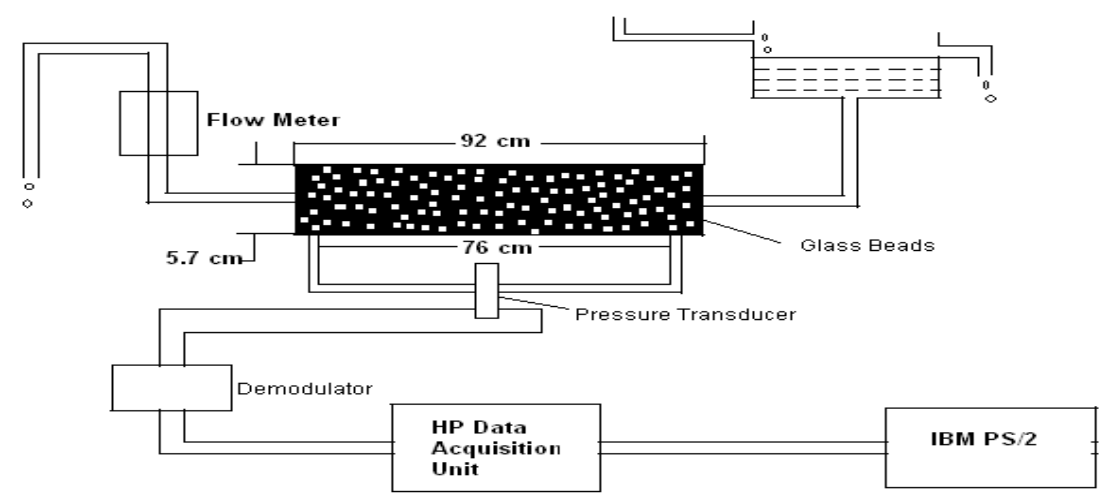

Fig. 5: Schematic diagram of the experimental set up after Kececioglu \& Jiang (1994).

Bhattacharya and Basack (2005) performed a laboratory based study to provide a theoretical model for nonlinear flow of saline water through a granular porous medium. They also studied inter-dependency of the fluid rheological properties like kinematic viscosity and density with saline water of different concentrations. The work is significantly for investigators studying the phenomenon of saline water intrusion into costal aquifers.

\section{Field Based Studies}

Goswami (1968) conducted a field based study in the coastal aquifer at Digha, Purba Midnapur, West Bengal, India (Fig. 6). To define the distribution and movement of the saline and fresh groundwater, a geohydrological survey was carried out by sinking Auger bore holes and testing the water quality. The study area was observed to consist of fine to coarse grain sand with occasional soft clay lenses. From the chemical analysis, the interface between saline water and fresh water was drawn for each of the well locations. The ratio of chloride/bicarbonate was used as an index for saline water intrusion. The seasonal and yearly variation of the interface was also investigated. For daily tidal oscillation, minor movements of the interface were observed. It was observed that wide deviations from the theoretical "Herzberg Ratio" have been notified in this area. The depth of the interface in the study was much less than that calculated on the basis of the Ghyben- Herzberg principle ( Fig. 7).

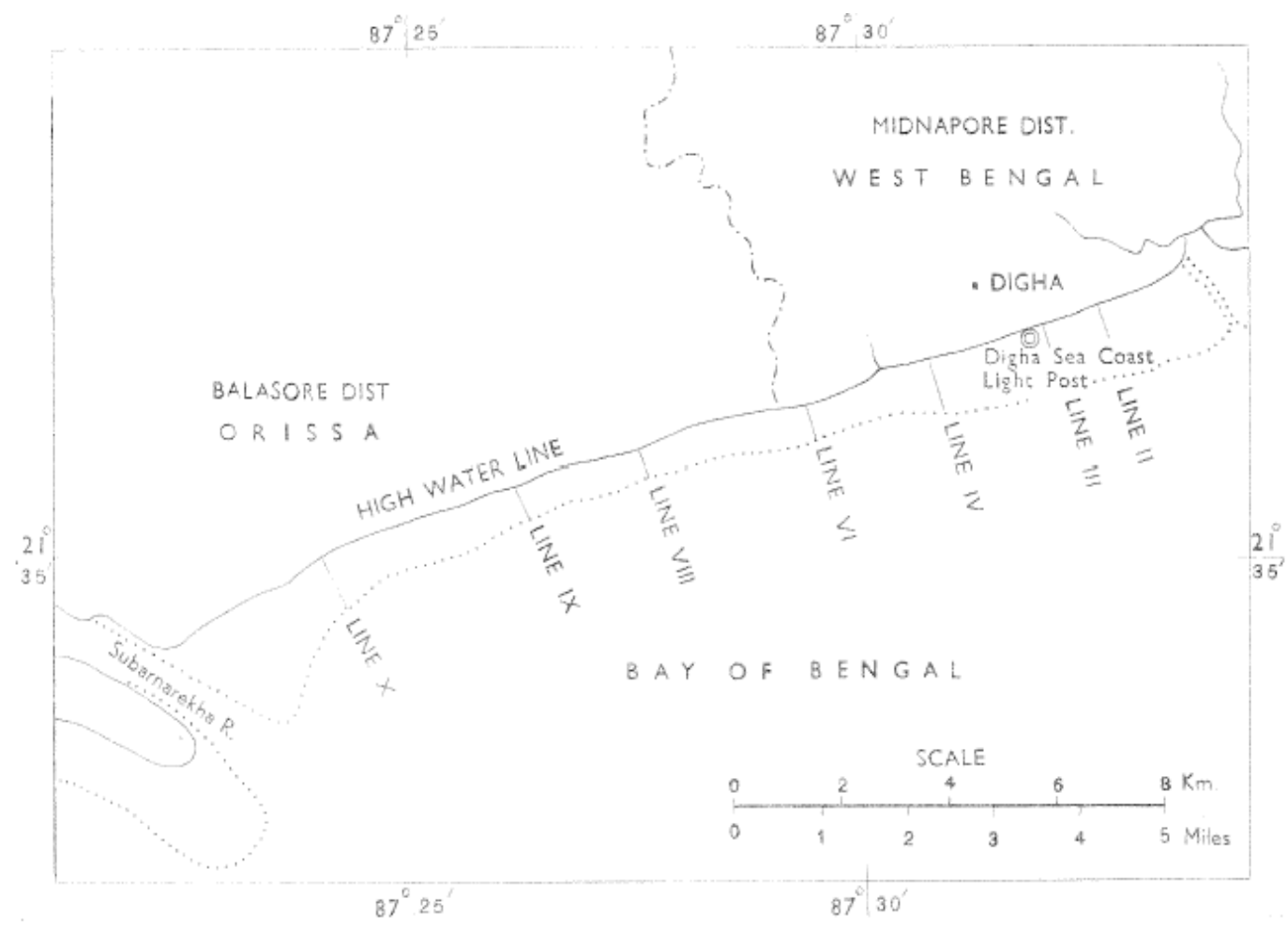

Fig. 6: Map showing the study area after Goswami,1968. 


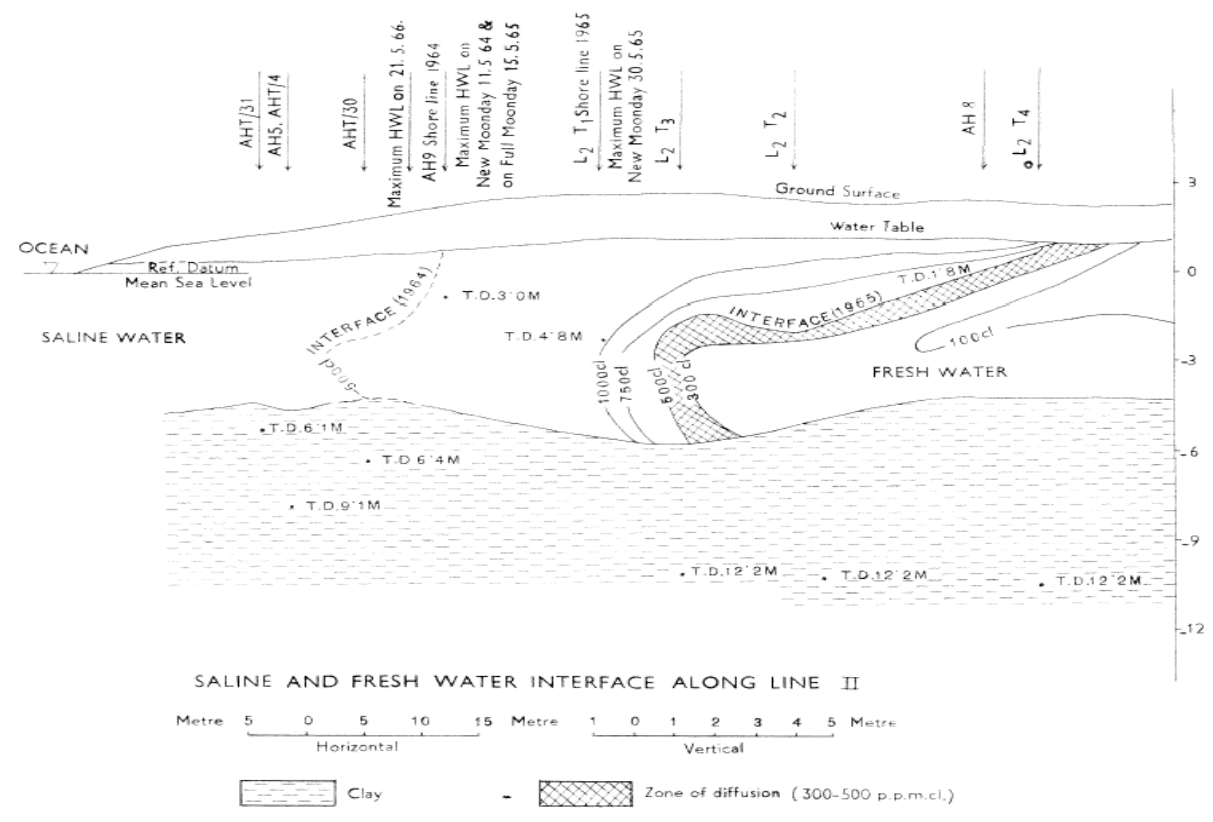

Fig. 7: A typical view showing the saltwater-freshwater interface (after Goswami,1968).

Barlow (2003) conducted a significant field based study on groundwater quality and flow in Atlantic Coast, USA, in the light of saline water intrusion. He also discussed the detection, monitoring and management techniques of the saltwater intrusion in the study area. A critical study of groundwater and coastal ecosystems together with the challenge and opportunity has also been discussed by the author. The author also constructed line of equal chloride concentration in groundwater at Southwestern Florida (Fig. 8).

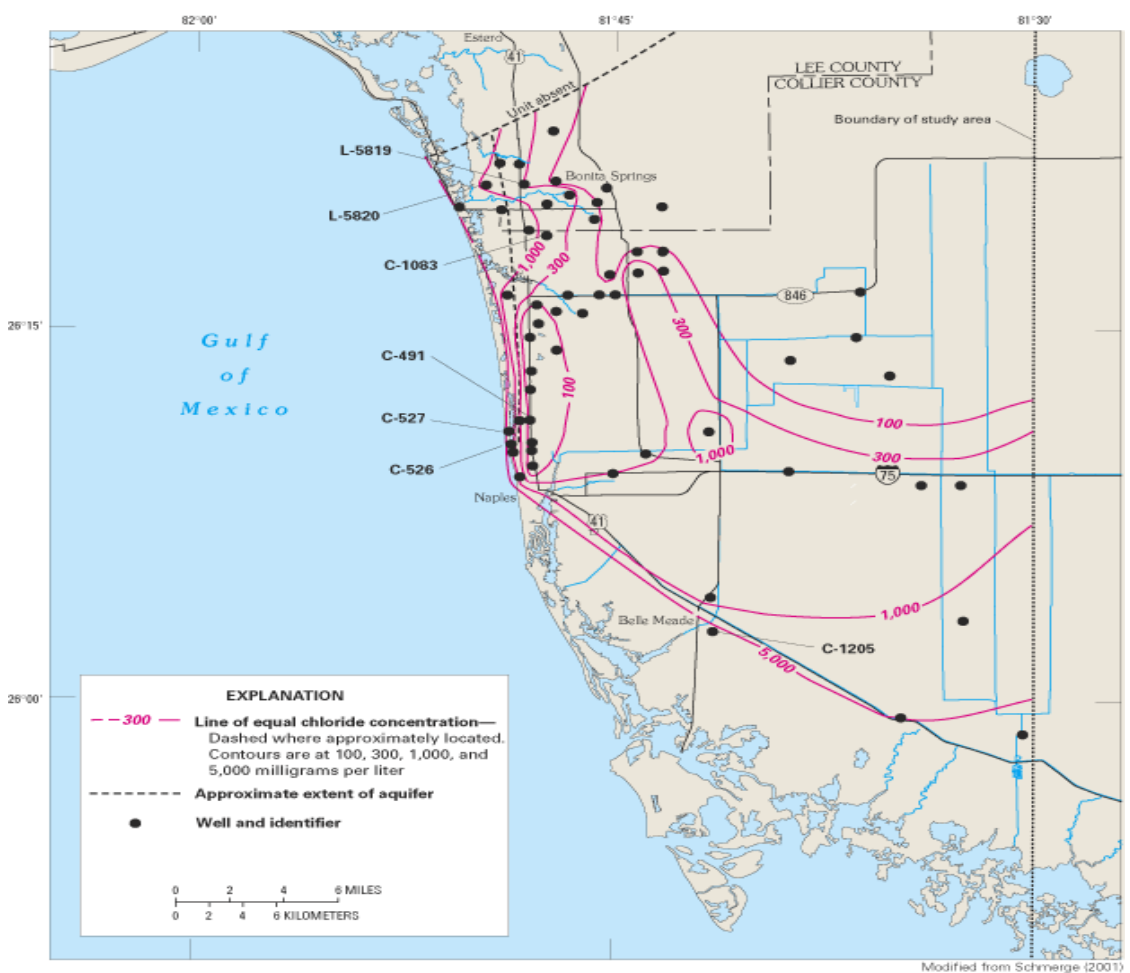

Fig. 8 : Line of equal chloride concentration in groundwater at Southwestern Florida (Barlow, 2003). 
Papadopoulou et al. (2005) conducted a field based study on analysis and control of saline water intrusion in the industrial zone of the City of Herakleio in Greek islands. The geology and saline zone of the study area were mapped from the geophysical measurement (Fig. 9). Also the suitability of different management techniques were proposed to control the saltwater intrusion, specifically artificial recharge by injection well (Fig 10).

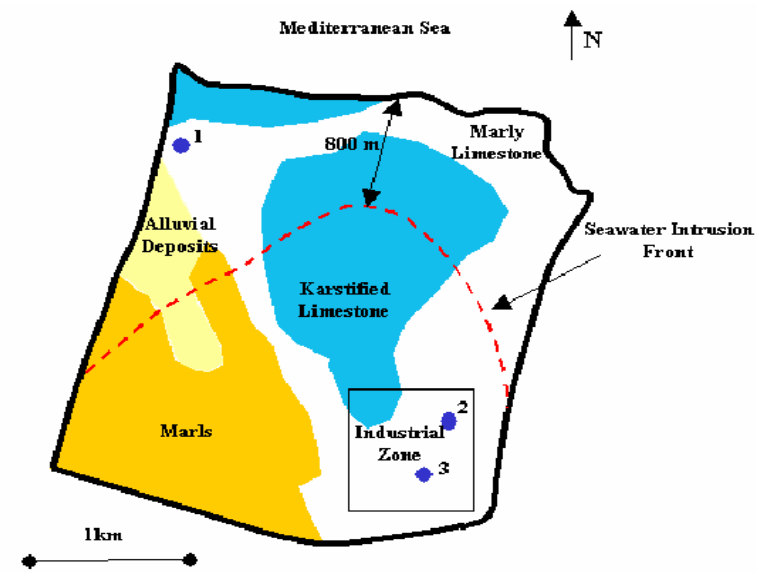

Fig. 9: Simulated saltwater front (after Papadopoulou et al., 2005)

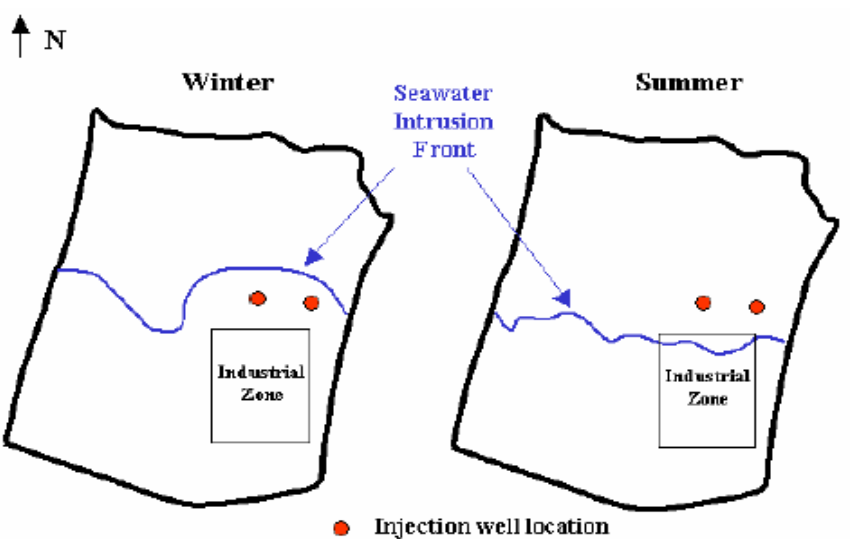

Fig. 10: Recharge by injection wells (after Papadopoulos et al., 2005)

IV. INFERENCES FROM AVAILABLE LITERATURE

From the previous section, it is evident that significant research and development has already been carried out by various scientists, engineers and researchers at different parts of the world in the field of analysis and control of saline water intrusion into coastal aquifers and other relevant areas. Amongst the important works, the most significant contributions are briefly reviewed, starting from the year of 1968 to till 2009, these contributions are broadly classified into three categories, viz., theoretical contributions (analytical and numerical studies), laboratory-based experimental works and field-based studies.

As observed, the different types of theoretical works that have been done are broadly based on two categories such as: (i) namely using the sharp interface concept e.g. Mahesha (2009), Goswami (1968), (ii) using the brackish interface concept e.g. Li and Yeh (1968) and Xue et al. (1995). Laboratory-based experimental works have been done include Fand et al. (1987), Kececioglu and Jiang (1994) and Bhattacharya and Basack (2005).

Field-based studies have been conducted by various researchers such as Goswami (1968), Barlow (2003) and Papadopoulou et al. (2005). Only Goswami (1968) has studied the nature and position of the interface and delineated the fresh and saline groundwater bodies within the aquifer of Digha beach, Purba Midnapur, West Bengal, India. The depth of the interface was found to be much less than that calculated on the basis of the Ghyben-Herzberg principle. However, the work is very old and the prescribed model is in need of updatation. Gaps do exist in knowledge regarding the modelling of the hydrogeology, aquifer system, subsurface stratification, water quality parameters, pre-monsoon, post-monsoon depth to water level and pre- monsoon piezometric surface contour of the study area of Purba Midnapur, West Bengal. Papadopoulou et al. (2005) 
proposed different management scenarios to prevent further ingress of the saline water intrusion front in the industrial zone of the City of Herakleio in Greek islands. Artificial recharge of fresh water is proposed as part of the solution.

From the brief review of these past research works, the author has observed that there are apparent shortcomings in the work of various researchers done so far and there is substantial scope for a thorough and detailed investigation to study the basic phenomenon of saline water intrusion into coastal aquifers of Purba Midnapur district, West Bengal, India, its causes, effects and remedial measures.

\section{HYDROGEOLOGY OF PURBA MIDNAPUR}

Groundwater development and management studies in parts of Purba Medinipur district has been undertaken to study the extension of saline aquifers \& effect of high tidal waves on phreatic aquifers and to study the impact of large scale groundwater development on groundwater regime including saline water ingression. Water level in Purba Midnapur district varies from 3 to $15 \mathrm{~m}$ below ground level during pre monsoon period [Fig. 11 ] and 4-12 m below ground level in post monsoon period [Fig. 12 ], below the dune sand clay bed occur down the depth of $70 \mathrm{~m}$ below ground level. Alteration of sand and clay bed occurs down to a depth of $450 \mathrm{~m}$ below ground level. Generally brackish water found in all the aquifers below sand dunes up to the depth of $450 \mathrm{~m}$ below ground level over a small area around Contai. Fresh water aquifer occurs within 120 to $300 \mathrm{~m}$ to below ground level towards south east of contai in Mukundpur, Baijapur and Sophiabad. (1)Fresh water is absent in some places in the detailed study area of Contai I, II \& III blocks where the tubewell is not feasible due to high salinity content, (ii) Desiltation of existing ponds in Contai area is suggested, (iii) Excavation of new ponds in the waste land area, (iv) Haldia Industrial Complex in Purba Medinipur district has been notified, consequently indiscriminate withdrawal of groundwater has been restricted. Haldia Development Authority has arranged to supply the surface water to meet the water demand. Hence, roof top rain water harvesting structures should be adopted for conservation of rain water in industrial sector for non drinking purposes.

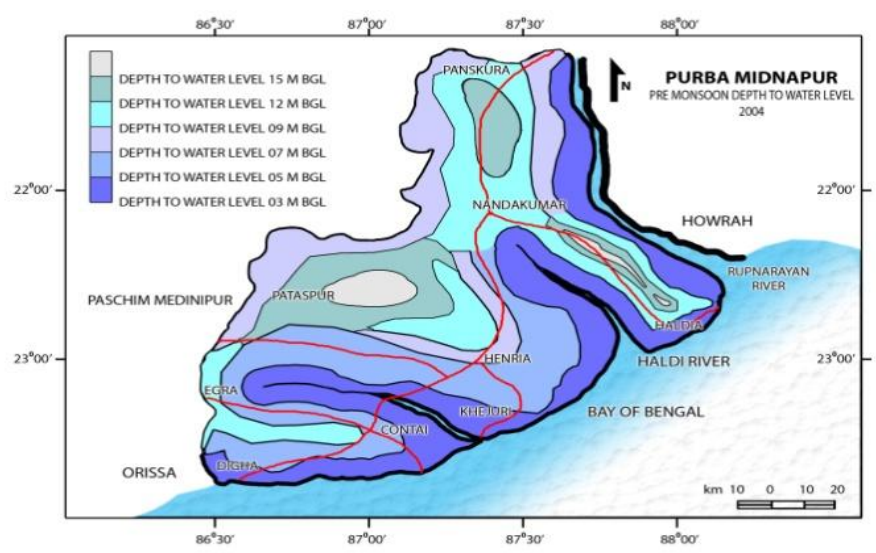

Fig. 11: Pre Monsoon depth to water level 2004 in Purba Midnapur, West Bengal.

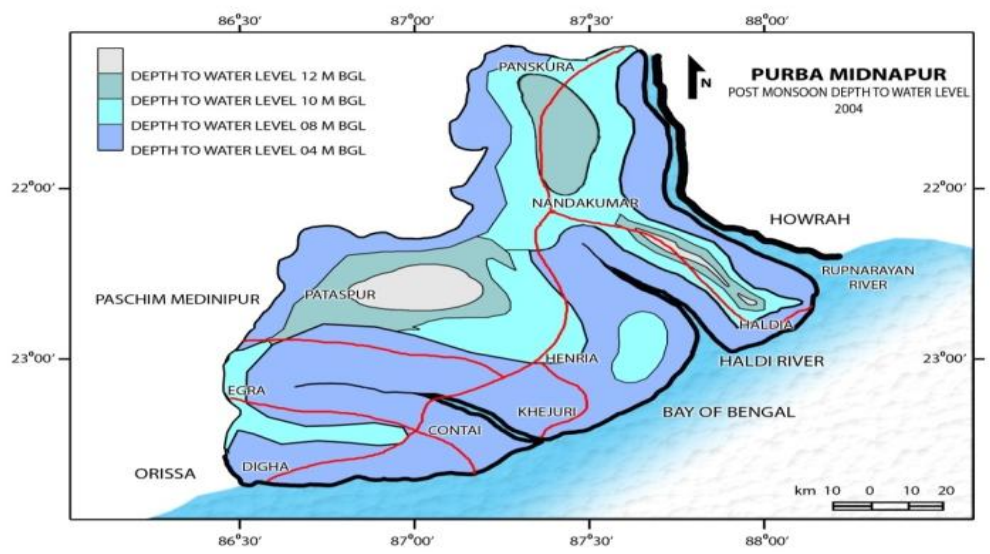

Fig. 12: Post Monsoon depth to water level 2004 in Purba Midnapur, West Bengal. 


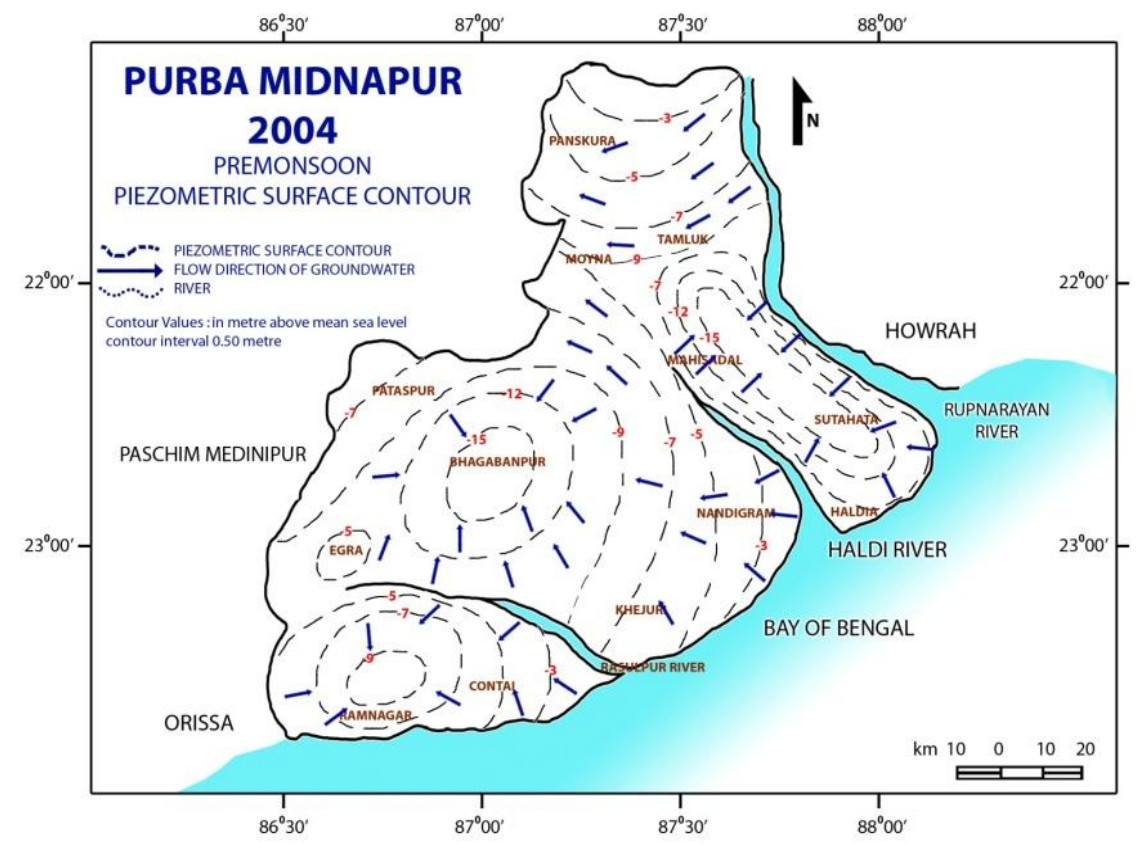

Fig. 13 : Pre Monsoon piezometric surface contour [ 2004 ] in Purba Midnapur, West Bengal.

\section{D VIEW OF PIEZOMETRIC SURFACE OF PURBA MIDNAPUR} PRE MONSOON 2006

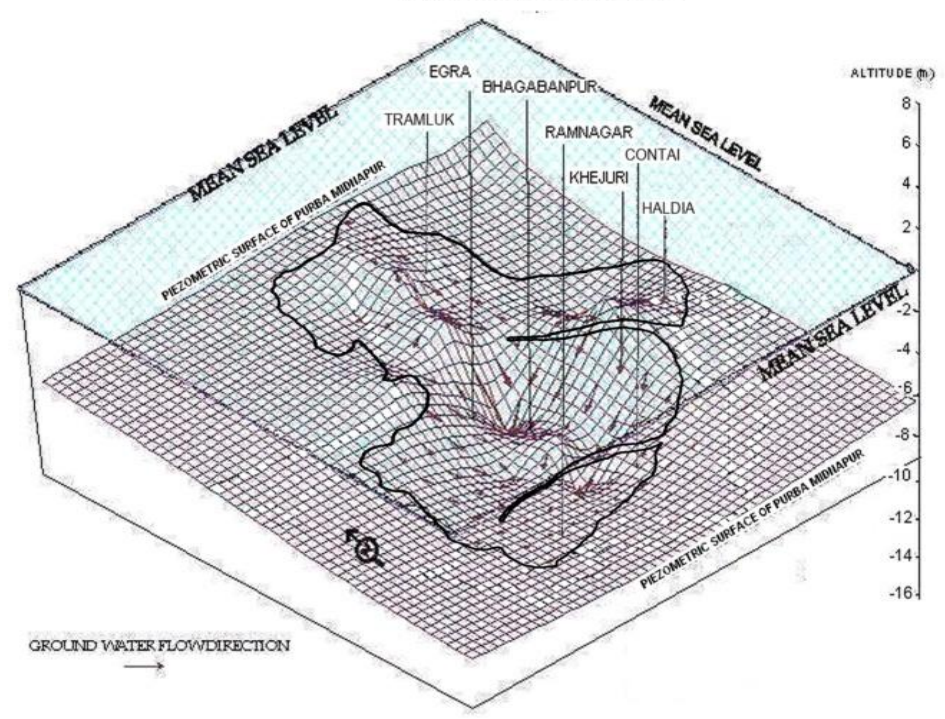

Fig. 14: 3D view of piezometric surface pre monsoon [ 2006 ] of Purba Midnapur, West Bengal.

\section{GEOCHEMICAL INVESTIGATION}

Groundwater samples from different deep tube wells of Public Health Department (Govt. of West Bengal) in coastal blocks of Purba Midnapur district have been collected from the tube wells/ bore wells and analyzed at the Chemical Laboratory of State Water Investigation Directorate, Govt. of West Bengal, Sech Bhavan ( $3^{\text {rd }}$ floor), Kolkata-700091 for various chemical parameters determination. Fig. 15 shows the geographical location of the study area. The parameter includes $\mathrm{pH}$, electrical conductivity, total dissolved solids, and anions such as carbonates, bicarbonates and chlorides [Ref. Table 1].

\section{Contai Municipality Town,West Bengal}

Contai town is the head quarter of Contai sub division in the district of Purba Midnapu, West Bengal, India. The total area of the town is $14.30 \mathrm{sq} . \mathrm{km}$. The town is very near to the sea coast of Bay of Bengal and the sea resort town of Digha is only $32 \mathrm{~km}$. away from Contai town. 


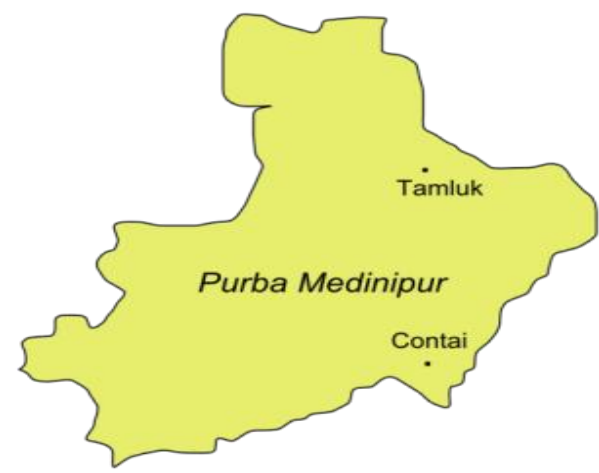

Fig. 15: Key location of Contai Municipality town, Purba Midnapur.

Table 1: Test result of water samples collected from 20 nos. well within the area of Contai Municipality. (Date of sample collection, 21.05.2006 \& 17.07.2006).

\begin{tabular}{|c|c|c|c|c|c|c|c|c|c|}
\hline $\begin{array}{l}\text { Sl. } \\
\text { No. }\end{array}$ & Location of well & $\mathrm{pH}$ & $\begin{array}{l}\text { Turbi- } \\
\text { dity } \\
\mathrm{Mgl}\end{array}$ & $\begin{array}{c}\text { Total } \\
\text { Hardne } \\
s \\
\mathrm{Mg} / \mathrm{l}\end{array}$ & $\begin{array}{c}\text { Chloride } \\
\mathrm{Mg} / \mathrm{l}\end{array}$ & $\begin{array}{l}\text { Nitrat } \\
e \\
\mathrm{Mg} / \mathrm{l}\end{array}$ & $\begin{array}{l}\text { Iron } \\
\mathrm{Mg} / 1\end{array}$ & $\begin{array}{c}\text { TD } \\
\mathrm{S} \\
\mathrm{Mg} \\
\mathrm{l}\end{array}$ & $\begin{array}{c}\text { Electrical } \\
\text { Conductivi } \\
\text { ty }\end{array}$ \\
\hline 01. & Contai-Housing Complex. & 6.73 & 0.48 & 216 & 159.00 & - & 0.04 & $\begin{array}{c}121 \\
0\end{array}$ & 2440 \\
\hline 02. & Contai-Central-Bus Stand & 6.56 & 2.5 & 232 & 84.80 & - & 0.27 & $\begin{array}{c}110 \\
0\end{array}$ & 2220 \\
\hline 03. & Contai Police Station & 6.85 & 0.71 & 340 & 254.40 & - & 0.18 & $\begin{array}{c}192 \\
0\end{array}$ & 3830 \\
\hline 04. & Athilagoni-Near-Kali Mandir & 7.21 & 0.98 & 90 & 300.50 & $<0.90$ & 0.34 & 910 & 890 \\
\hline 05. & Krishnakanta Pukurpar & 6.98 & 2.67 & 310 & 231.00 & $<0.90$ & 0.42 & 750 & 1170 \\
\hline 06. & Contai PHE Office & 7.54 & 3.87 & 350 & 240.50 & $<0.90$ & 1.47 & 710 & 1200 \\
\hline 07. & Contai SDO Office & 7.32 & 3.00 & 300 & 222.00 & 30.10 & 0.57 & 659 & 1300 \\
\hline 08. & $\begin{array}{l}\text { Canalpar-near } \\
\text { Bhabatarini Mandir }\end{array}$ & 7.61 & 4.87 & 320 & 220.50 & 33.10 & 0.27 & 650 & 1400 \\
\hline 09. & Contai SD Hospital & 6.98 & 0.76 & 320 & 220.50 & 33.10 & 0.27 & 610 & 1890 \\
\hline 10 & Digha By-pass & 8.21 & 0.87 & 980 & 1141.00 & 1.00 & 1.24 & $\begin{array}{c}213 \\
0\end{array}$ & 1908 \\
\hline 11 & Contai PK College & 6.81 & 5.00 & 110 & 35.00 & 16.70 & 0.03 & 201 & 1400 \\
\hline 12 & Kshetra Mohan High School & 6.45 & 5.01 & 420 & 326.50 & $<0.90$ & 0.89 & 910 & 1600 \\
\hline 13 & Contai High School & 6.94 & 4.01 & 230 & 130.00 & 44.10 & 0.06 & 330 & 1700 \\
\hline 14 & Karkuli-near-Dr. G.K.Ghosh & 7.01 & 3.78 & 330 & 691.00 & $<0.90$ & 1.58 & $\begin{array}{c}180 \\
0\end{array}$ & 1800 \\
\hline 15 & Kharagpur By-pass & 7.30 & 3.67 & 570 & 339.00 & $<0.90$ & 0.82 & 930 & 1980 \\
\hline 16 & Mechada By-pass & 7.21 & 3.87 & 210 & 174.00 & $<0.90$ & 0.48 & 630 & 2100 \\
\hline 17 & $\begin{array}{llll}\text { Susanta } & \text { Sarani near } & \text { Kali } \\
\text { Mandir } & & & \\
\end{array}$ & 8.43 & 3.89 & 160 & 212.00 & 39.60 & 0.18 & 630 & 2300 \\
\hline 18 & $\begin{array}{l}\text { Padmapukuria near Dr. Bidhan } \\
\text { Roy }\end{array}$ & 6.86 & 4.89 & 170 & 57.50 & $<0.90$ & 0.30 & 150 & 2400 \\
\hline 19 & Kishore-Nagar-High School & 7.83 & 4.86 & 180 & 100.00 & $<0.90$ & 0.56 & 210 & 2010 \\
\hline 20 & Municipality Dormitory & 7.32 & 3.87 & 100 & 38.00 & 7.20 & 0.85 & 129 & 1890 \\
\hline
\end{tabular}




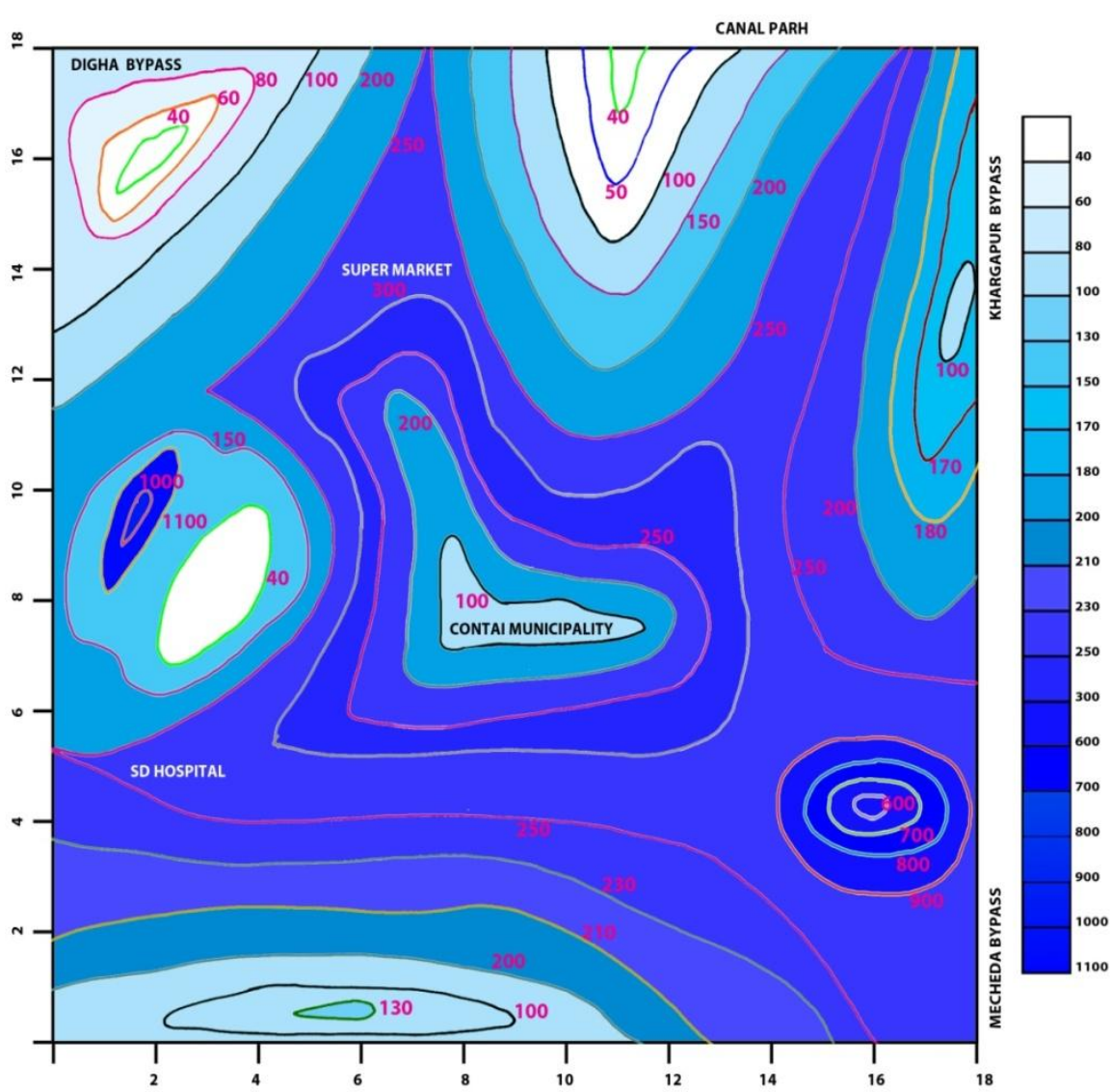

Fig. 16: Map showing contours of Chloride of well (2006) in (ppm) in Contai Municipality area, Purba Midnapur, West Bengal.

The water samples have been collected from the well at Contai Municipality town area. Based on chemical analysis (Table 1) conducted, the data obtained from Chloride concentration (ppm) has been plotted in the Contai Municipality town area and relevant contours have been drawn (Fig. 16). As observed, the Chloride concentration varies from as high as 1100 ppm at Darua to as low as 20 ppm at Kanal-Parh and Digha Bypass. The variations of the Chloride concentration in the aquifer at the depth taken were found to be quite irregular pattern. At some locations the Chloride concentration is quite high such as at Monoharchak (1000 ppm) and Mechada bypass $(900 \mathrm{ppm})$. Conversely, at few locations, the Chloride concentration is significantly low like Hatabari $(20 \mathrm{ppm})$, Athelaguri $(50 \mathrm{ppm})$ and Kumarpur $(60 \mathrm{ppm})$ etc. Within the Contai Municipality area wide variations in salinity concentration is observed which can be, at least partially attributed to the high degree of spatial heterogeneity of the aquifer underlying the area.

\section{Water Scenario}

Proposed site will be around $8 \mathrm{~km}$. from Contai town, in Contai town, there are hand tube wells yielding sweet water within a short distance from the Municipality in the South- Eastern direction. So, it is proposed to sink the tube wells groundwater with in the Contai subdivision area. Orissa coastal canal which flows from north-west to north -east carries saline water and same for the Rasulpur River. No impounded non saline water is available anywhere near the area. It has been found that the Contai town with its surrounding rural areas of about 45 sq.miles forms a saline zone. The existing water supply scheme for Contai Municipality has got 2 no. deep tube well sunk out side this saline zone at Mukundapur. These deep tube wells have been functioning satisfactory for nearly a decade. Eight (8) nos. deep tube wells were sunk in the year 1978 at Rautora and Kapasda in the West, Nachinda in the North and Mukundapur in the East for water supply to the vast rural areas surrounding the Contai Municipality. Out of these 8 tube wells, 4 tube wells have so far gone out of order due to chock age of strainers by fine sand. All of these chocked tube wells were located in the West side i.e. at Rautora and Kapasda areas. While the exact cause of failure of tube wells in this area within a short time is not known, chloride- content in the water of some of the tube wells are known to have increased significantly before their failure [Figs. 17]. This gives rise to the apprehension of a possible saline water intrusion in the aquifer. Deep tube wells sunk in the North at Nachinda, $14 \mathrm{kms}$ always from Contai town are still functioning 
satisfactorily. Sinking of tube wells for the present water supply augmentation scheme for Contai municipality at Nachinda is considered but had to be discarded considering the prohibitive cost of $14 \mathrm{~km}$. length of rising main. Two tube wells of the existing Municipal scheme and other two tube wells of the rural scheme have been sunk at Mukundapur in the North-East direction beyond the saline area, at a distance of about $8 \mathrm{~km}$. from the existing elevated reservoir, in Contai town. As these are already tube wells running successfully in this area further tube wells required is also proposed to be sunk here for zone (zone-II). It is proposed to sink the tube wells required for zone-I around Majna area on Contai Depal road. Big dia. tube well sunk in this area for Majna rural water supply scheme is functioning satisfactorily. The tube wells for zone-III at mouja Dauki along from Contai to Junput, should keep a safe distance from the saline zone boundary. Prior to sinking of tube wells, a detailed study of the well field should be undertaken by exhaustive trial boring in this area. A good water bearing strata of thickness of $30 \mathrm{~m}$ is expected here at a depth of $180 \mathrm{~m}$ below G.L.

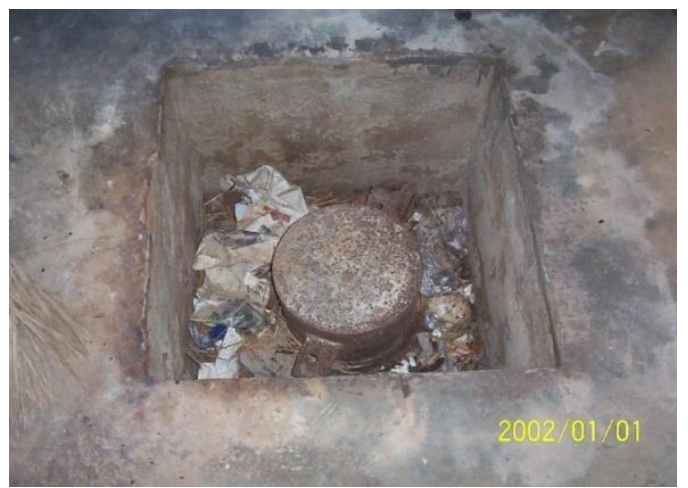

Fig. 17: The Kapasda Water Supply Scheme P.H.No-1, abandoned due to saline water intrusion, Contai, Purba Midnapur.

\section{CONCLUSSIONS}

- The Rasulpur river acts as a conduit for saline water intrusion and relatively porous aquifer in the vicinity as the village Heria causes a salinisation of the ground water in that area. As a result of which the $\mathrm{Cl}^{\mathrm{C}}$ concentration in that area are high in spite of much lower $\mathrm{Cl}^{\square}$ concentration near the coast except for one site which appears to be due to a local high hydraulic conductivity area.

- Contai town is in a saline prone area and the probable pathway of ingress of saline water into Contai is shown in saline water intrusion map of Purba Midnapur.

- Digha, on the seacoast, witnesses moderate salinity ingress due to low hydraulic conductivity of the aquifer of the area and this is reflected in the $\mathrm{Cl}^{\square}$ concentrations of two sites deeper inland whose low salinity reinforces the understanding that the hydraulic conductivity (effective horizontal hydraulic conductivity) is low on the region. Enhanced $\mathrm{Cl}^{\square}$ concentration is of sporadic concern in different parts of Purba Midnapur. It has been reported that a number of deep tube wells have become defunct of an enhanced level.

- The depth to piezometric surface is within $8 \mathrm{~m}$ below ground level. Due to large scale withdrawal of ground water in Sutahata - Mahishadal - Haldia sector drawdown of piezometric head to the tune of 1.6 metres over the last ten years has been noted. In Contai area in the southwest, groundwater occurs under water table conditions in the sand dunes overlying the upper clay blanket. Underlying this fresh unconfined groundwater is saline down to $235 \mathrm{~m}$ depth with chloride content upto $17000 \mathrm{ppm}$.

- The coastal zone of Purba Midnapur by its own virtue possesses high geologic heterogeneity. The soil of low hydraulic conductivity is interspersed with soil of high hydraulic conductivity in an almost random manner. The pattern of variation of salinity concentration is heterogeneous in three dimensional spaces. Some inland locations such as Sharkhanchak, Kalindi and Betkundu have been showing greater salinity than corresponding coastal areas due to ingress of sea water through the preferential path. The study finds that the interface of saline water intrusion is progressively moving inwards in the zones of Nachinda, Contai, Mukutshila and Haldia.

- For the year 2004 and 2006 (Fig. 11, Fig. 12 \& Fig. 13), the pre-monsoon piezometric surface contours show depressions near Ramnagar, Bhagbanpur, and Sutahata. In the prevailing climatic scenario in the area, the premonsoon condition is far more critical as compare the post-monsoon condition. Therefore, evaluation of the potential for salinisation is carried out considering the pre-monsoon position. It is very clear that the Ramnagar area which includes the tourist resort of Digha and the town of Contai, is highly prone to saline water intrusion as is the Sutahata area which includes the industrial town of Haldia. Immediate and urgent measures are needed to push back saline water encroachment in these areas. 
- The study shows that the artificial recharge by rainwater harvesting through percolation pond, injection well and optimisation of pumping location will also help in reducing the saline water intrusion in the area of Heria, Bajkul, Tamluk, Sutahata and Mahishadal.

\section{REFERENCES}

[1] Andrade, J.S., Costa, U.M.S., Almeida, H.A. and Stanley, H.E. (1999) "Inertia Effects on Fluid through Disordered Porous Media”, Journal of Physical Review Letters, Vol. 82, pp. 5249-5252.

[2] Bhattacharya A.K. (2002) "Saline water Intrusion into Coastal Aquifers of West Bengal, India", International Conference on Low Lying Coastal Areas Hydrology and Coastal Zone Management, Bremerhaven, Federal Republic of Germany, pp. 197-200.

[3] Barlow, M. (2003) "Freshwater-Saline Water Environments of the Atlantic Coast", U.S. Geological Survey Report (USGS), (http://www.pubs.usgs.gov/circ/2003/circ1262).

[4] Bhattacharya, A.K., Basack, S., and Maity, P. (2004) "Groundwater Extraction in the United Arab Emirates Under the Constraint of Saline Water Intrusion” the Journal of Environmental Hydrology, Vol. 12, Paper 6, No.6, April, 2004. pages 1-5.

[5] Basack, S., Bhattacharya, A.K., Sahana, C., and Maity, P. (2010). “A Study on Saline Water Intrusion and Fresh Water Recharge relevant to Coastal Environment", WSEAS Transaction on Fluids Mechanics ( ISSN: 1790-5087 ) Including in ISI/SSI Web of Science and Web of Knowledge, issue 3, Volume 5, July 2010 , pages 80-90,[ www.wseas.org ].

[6] Fand, R.M., Kim, B.Y.K., Lam, A.C.C. and Phan, R.T. (1987) “ Resistance to the Flow of Fluids through Simple and Complex Porous Media Whose Matrices are Composed of Randomly Packed Spheres ", Journal of Fluids Engineering, 1987 Sept, Vol.109, pp. 268-274.

[7] Goswami, A.B. (1968) "A Study of Salt Water Encroachment in the Coastal Aquifer at Digha, Midnapore District, West Bengal, India”, Bulletin, International Association of Scientific Hydrology, Vol.13, No.3, pp.77-87.

[8] Kececioglu, I. and Jiang, Y. (1994) "Flow through Porous Media of Packed Spheres Saturated With Water”, Journal of Fluids Engineering, 1994 March, Vol.116, pp. 164-170.

[9] Karanth, K.R (1990) “Groundwater Assessment Development and Management”, Tata McGraw-Hill Publishing Co. Ltd., New Delhi.

[10] Li, Wen-Hsiung and Yeh Gour-Tsyh (1968) "Dispersion at the Interface of Miscible Liquids in a Soil", Journal of Water Resources Research, 1968 April, Vol. 4, No. 2, pp. 369-377.

[11] Mahesha, A (2009) "Conceptual Model for the Safe Withdrawal of Freshwater from Coastal Aquifers", Journal of Environmental Engineering, Vol. 135, No. 10, October 1, 2009.asce, ISSN 0733-9372/2009/10, pp. 980-988.

[12] Papadopoulou, M.P. et al (2005) "Modeling the Saltwater Intrusion Phenomenon in Coastal Aquifers - A Case Study in the Industrial Zone of Herakleio in Crete”, Global Nest Journal, Vol. 7, No 2, pp 197-203.

[13] Rudraiah, N. (2001) "Non-Linear Study of Stratified Fluid through Porous Media", Journal of porous media, June 2001, Vol.4 (2).

[14] Raghunath, H.M. (1987) "Ground Water", 2nd Edition, Wiley Eastern Ltd., New Delhi.

[15] Xue, Y., Xie, C. and Wu, J. (1995) “A Three Dimensional Miscible Transport Model for Seawater Intrusion in China”, Journal of Water Resources Research, 1995 April, Vol. 31, No. 4, pp. 903-912. 